\title{
Distinct clinicopathological features in metanephric adenoma harboring BRAF mutation
}

\author{
Anna Caliò ${ }^{1,2}$, John N. Eble ${ }^{1}$, Ondrej Hes $^{3}$, Guido Martignonii, ${ }^{2,4}$ Saul E. Harari ${ }^{1}$, \\ Sean R. Williamson ${ }^{5}$, Matteo Brunelli ${ }^{2}$, Adeboye O. Osunkoya ${ }^{6}$, Lisha Wang7, Eva \\ Comperat ${ }^{8}$, Antonio Lopez-Beltran ${ }^{9}$, Mingsheng Wang ${ }^{1}$, Shaobo Zhang ${ }^{1}$, Kendra L. \\ Curless ${ }^{1}$, Kristin M. Post ${ }^{1}$, Hsim-Yee Chang ${ }^{1}$, Claudio Luchini ${ }^{1,2}$, Lee Ann Baldrige ${ }^{1}$, \\ Gregory T. MacLennan ${ }^{10}$, Rodolfo Montironi ${ }^{11}$, David J. Grignon ${ }^{1}$ and Liang Cheng ${ }^{1}$ \\ ${ }^{1}$ Department of Pathology and Laboratory Medicine, Indiana University School of Medicine, Indianapolis, Indiana, USA \\ ${ }^{2}$ Department of Pathology, University of Verona, Verona, Italy \\ ${ }^{3}$ Department of Pathology, Charles University Hospital Plzeň, Pilsen, Czech Republic \\ ${ }^{4}$ Department of Pathology, Pederzoli Hospital, Peschiera, Italy \\ ${ }^{5}$ Department of Pathology and Laboratory Medicine, Henry Ford Health System, Detroit, Michigan, USA \\ ${ }^{6}$ Department of Pathology, Emory University School of Medicine, Atlanta, Georgia, USA \\ ${ }^{7}$ Michigan Center for Translational Pathology, University of Michigan, Ann Arbor, Michigan, USA \\ ${ }^{8}$ Department of Pathology, Groupe Hospitalier Pitié-Salpêtrière, Paris, France \\ ${ }^{9}$ Unit of Anatomical Pathology, Department of Surgery, Faculty of Medicine, Cordoba, Spain and Champalimaud Clinical \\ Center, Lisbon, Portugal \\ ${ }^{10}$ Departments of Pathology and Laboratory Medicine, Case Western Reserve University, Cleveland, Ohio, USA \\ ${ }^{11}$ Department of Pathological Anatomy and Histopathology, School of Medicine, Polytechnic University of The Marche Region \\ (Ancona), Ancona, Italy \\ Correspondence to: Liang Cheng, email: liang_cheng@yahoo.com \\ Keywords: kidney, metanephric adenoma, BRAF, nephroblastoma/Wilms tumor, immunohistochemistry \\ Received: March 08, $2016 \quad$ Accepted: July 07, $2016 \quad$ Published: August 08, 2016 \\ Copyright: Caliò et al. This is an open-access article distributed under the terms of the Creative Commons Attribution License 3.0 \\ (CC BY 3.0), which permits unrestricted use, distribution, and reproduction in any medium, provided the original author and source \\ are credited.
}

\section{ABSTRACT}

BRAF mutation recently has been reported in metanephric adenoma. We sought to determine the clinical and morphologic features of BRAF-mutated metanephric adenoma and to correlate BRAF mutation with BRAF V600E immunohistochemical staining results. A series of $\mathbf{4 8}$ metanephric adenomas and 15 epithelial-predominant nephroblastomas were analyzed for the occurrence of BRAF mutation (BRAF V600E/ V600E complex, BRAF V600D, BRAF V600K and BRAF V600R) using the BRAF RGQ PCR kit (Qiagen). Immunohistochemistry was performed using monoclonal mouse antibodies against $\mathrm{p}^{16^{\mathrm{INK}} 4}$ and VE1 (Spring Bioscience), recognizing the BRAF V600E mutant protein. Forty-one of 48 cases ( $85 \%$ ) showed BRAF V600E mutation; none of the other BRAF variants was detected. Of 41 BRAF-mutated metanephric adenomas, 33 showed positive VE1 immunostaining (sensitivity $80 \%$, specificity $100 \%$ ); in all cases we detected $\mathrm{p} 16^{\mathrm{INK} 4}$ expression regardless of BRAF mutation status. All epithelial-predominant nephroblastomas were $B R A F$-wild-type and none expressed VE1. The following features were associated with BRAF V600E mutation: older patients $(p=0.01)$, female predominance $(p=0.005)$ and the presence of a predominantly acinar architecture $(p=0.003)$. In summary, BRAF-mutated metanephric adenomas were 


\section{associated with older age, female predominance, and the presence of a predominant acinar component. A subset (20\%) of BRAF-mutated metanephric adenomas was not detected by VE1 immunostaining.}

\section{INTRODUCTION}

Metanephric adenoma of the kidney is an uncommon benign neoplasm which is usually asymptomatic and discovered incidentally. These tumors mostly occur in middle-aged individuals, with a female predominance (2:1), although the age distribution is broad, ranging from children to the elderly [1-4]. On gross examination, metanephric adenomas are typically circumscribed, not-encapsulated, solid masses. Histologically, these neoplasms are typically composed of small epithelial cells arranged as tightly packed small acini. A hyalinized or edematous stroma is present occasionally. Psammoma bodies are common. The cells have scant cytoplasm, round nuclei, and variably-present nuclear grooves. However, metanephric adenomas may assume a variety of architectures and may thus present a diagnostic challenge to the pathologist. The main differential diagnostic considerations for metanephric adenoma are epithelialpredominant nephroblastoma in children and the solid variant of papillary renal cell carcinoma in adults. In challenging cases, immunohistochemistry and FISH techniques are helpful. With immunohistochemistry, metanephric adenomas usually label for WT1 and CD57 and are characteristically negative for CK7 and AMACR [5]. FISH can be used for analyzing chromosomes 7, 17 and Y. Metanephric adenoma lacks the gains of chromosome 7 and 17 and losses of $Y$ that are typical of papillary renal cell carcinoma [6].

Recently, somatic mutation of the BRAF (v-raf murine sarcoma viral oncogene homolog B1) oncogene, located on the long arm of chromosome 7, was identified as a common event in metanephric adenomas [7-12]. $\mathrm{BRAF}$ is a serine/threonine kinase that plays a critical role in the mitogen-activated protein kinase (MAPK) signaling pathway. The V600E mutation, which accounts for the vast majority of $B R A F$ alterations, induces phosphorylation of downstream targets leading to constitutive activation of the cascade. The same mutation has been implicated in the development of many tumors, including melanocytic nevi [13] and melanoma [14], papillary thyroid carcinoma [15], pilocytic astrocytoma [16], colonic adenocarcinoma [17], cholangiocarcinoma [18], borderline ovarian cancer [19], pulmonary adenocarcinoma [20], Langerhans cell histiocytosis [21] and hairy cell leukemia [22]. Of note, immunostaining with the VE1 antibody has been reported as reliable for the detection of $B R A F \mathrm{~V} 600 \mathrm{E}$ mutation in several of the above-mentioned neoplasms [23-29]. Regarding metanephric adenomas, only a few studies $[8,9,11]$ containing overall only 20 cases, have investigated the use of immunohistochemistry to detect $B R A F$ mutation.
In this study, we correlated $B R A F$ mutation, detected by molecular analysis, with $B R A F$ V600E immunohistochemical staining in a series of 48 metanephric adenomas and 15 epithelial-predominant nephroblastomas. In addition, we sought to identify clinical and histopathological features of metanephric adenomas harboring $B R A F$ mutation.

\section{RESULTS}

Of the 48 patients with metanephric adenoma, 31 were female and 17 were male (F:M ratio, 1.8:1). The median age at diagnosis was 54 years (range: 5 to 84 years) and the median size of the tumor was $4 \mathrm{~cm}$ (range from 1.1 to $8 \mathrm{~cm}$ ) (Table 1). Among the 15 epithelial-predominant nephroblastoma patients, 8 were female and 7 were male (F:M ratio, 1.1:1). The median age was 5 years (range, 8 weeks to 41 years). There were 3 tumors that occurred in adult patients $(27,35$, and 41 years, respectively), one female and two male (Table 2).

Microscopic examination of metanephric adenomas showed neoplasms composed of small, uniform and overlapping epithelial cells with scant cytoplasm, inconspicuous nucleoli and essentially no mitotic figures. These cells were arranged in a variety of architectural patterns (Figure 1). Simple tubules, acini and solid patterns were the most common. Papillary structures were present in 14 cases $(29 \%)$ and were the predominant pattern ( $>50 \%$ of the tumor) in 3. Glomeruloid bodies were present in 14 cases $(29 \%)$, and branching tubules were present in 24 cases $(50 \%)$. Eighteen cases $(38 \%)$ showed a variably thickened and usually discontinuous fibrous pseudocapsule. Fibrous septa that gave a vaguely multinodular appearance were recognized in 14 cases (29\%). Twenty-eight tumors (58\%) contained psammoma bodies, ranging from isolated and scattered to numerous. A few foamy macrophages were seen in only 3 cases (6\%). A stromal component was virtually absent in 4 cases $(8 \%)$. The remaining cases demonstrated edematous or hyalinized stroma or both (range from $5 \%$ to $40 \%$ of tumor volume).

$B R A F$ V600E mutations were identified in 41 of 48 cases $(85 \%)$ and none of the other $B R A F$ mutation variants was detected. Of these, 30 patients were women and 11 were men (F:M, 2.7:1). The median age was 57 years (range from 5 to 84 years) and the greatest dimension ranged from 1.4 to $8 \mathrm{~cm}$ (median $=3.9 \mathrm{~cm}$ ). Among the $7 B R A F$-wild-type cases, there was a striking male predominance ( $\mathrm{F}: \mathrm{M} 1: 6)(\mathrm{p}=0.0055)$, and the patients tended to be younger (median 33, range from 10 to 74) $(\mathrm{p}=0.014)$. Tumor size in $B R A F$-wild-type cases (median $=3.5$, range from 1.1 to 6.5 ) was similar to the $B R A F$ - 
Table 1: Clinical and histopathological features of $B R A F$-mutated and $B R A F$-wild-type metanephric adenomas

\begin{tabular}{|c|c|c|c|}
\hline Characteristic & BRAF mutated & BRAF wild type & P value \\
\hline Cases, n (\%) & $41(85)$ & $7(15)$ & \\
\hline \multicolumn{4}{|l|}{ Gender, n (\%) } \\
\hline Male & $11(27)$ & $6(86)$ & \multirow{2}{*}{0.0055} \\
\hline Female & $30(73)$ & $1(14)$ & \\
\hline Age median & 57 & 33 & 0.014 \\
\hline Size median & 3.9 & 3.5 & 0.71 \\
\hline \multicolumn{4}{|l|}{ Architecture } \\
\hline Pseudocapsule & 16 & 2 & 0.66 \\
\hline Fibrous septa & 12 & 2 & 0.99 \\
\hline \multicolumn{4}{|c|}{ Histologic pattern (range, $\%)^{*}$} \\
\hline Acini & $36(5-70)$ & $4(5-25)$ & 0.003 \\
\hline Solid areas & $27(5-100)$ & $6(5-50)$ & 0.41 \\
\hline Tubules & $25(5-60)$ & $5(10-50)$ & 0.74 \\
\hline Branching tubules & $19(5-40)$ & $5(5-20)$ & 0.35 \\
\hline Glomeruloid bodies & $11(5-40)$ & $3(15-30)$ & 0.32 \\
\hline Papillae & $12(5-80)$ & $2(20-35)$ & 0.91 \\
\hline \multicolumn{4}{|l|}{ Stroma } \\
\hline Hyalinized & $26(5-40)$ & $6(5-15)$ & 0.94 \\
\hline Edematous & $28(5-30)$ & $2(15-20)$ & 0.22 \\
\hline \multicolumn{4}{|l|}{ Other features } \\
\hline Psammoma bodies & 22 & 6 & 0.11 \\
\hline Foamy Histiocytes & 3 & 0 & \\
\hline \multicolumn{4}{|l|}{ Immunohistochemistry } \\
\hline VE1 positive, $\mathrm{n}(\%)$ & $33(80)$ & 0 & \\
\hline VE1 negative, n (\%) & $8(20)$ & $7(100)$ & \\
\hline \multicolumn{4}{|l|}{ 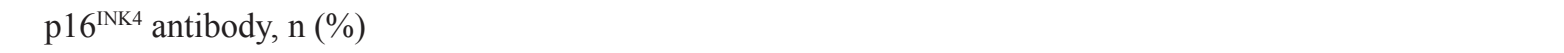 } \\
\hline $5-\leq 20 \%$ & $12(29)$ & $1(14)$ & 0.65 \\
\hline$>20 \%$ & $29(71)$ & $6(86)$ & \\
\hline
\end{tabular}

*The numbers indicated cases $B R A F$ mutated and $B R A F$ wild-type with distinct histopathological characteristics. The range of area occupied by each histological pattern was reported as a percentage in parenthesis.

mutated cases $(\mathrm{p}=0.71)$. Most BRAF-mutated cases exhibited a predominantly acinar architecture $(\mathrm{p}=0.003)$. Among 5 cases without this unique histologic feature, 4 were composed mostly of tubules and one mostly of papillae. The other morphological features were not associated with $B R A F$ mutational status. None of epithelial-predominant nephroblastomas had $B R A F$ mutation.
There was positive cytoplasmic immunolabeling for VE1 antibody in 33 of $41(80 \%)$ metanephric adenomas with $B R A F$ mutation (Figure 2). All VE1 immunostaining positive cases showed $B R A F$ V600E mutation, detected by Qiagen BRAF RGQ PCR kit. No nuclear staining was detected in any case. All cases of epithelial-predominant nephroblastoma were completely negative, correlating with their $B R A F$ wild-type status. Positive immunolabeling 
Table 2: Clinical, molecular and immunohistochemical features of epithelial-predominant nephroblastoma

\begin{tabular}{|c|c|c|c|c|c|}
\hline Case & Gender & Age (years) & $B R A F$ status & VE1 & p16 \\
\hline 1 & M & 3 & wild-type & 0 & $30 \%+$ \\
\hline 2 & $\mathrm{~F}$ & 8 weeks & wild-type & 0 & 0 \\
\hline 3 & $\mathrm{~F}$ & 27 & wild-type & 0 & $<5 \%+$ \\
\hline 4 & $\mathrm{~F}$ & 3 & wild-type & 0 & 0 \\
\hline 5 & $\mathrm{~F}$ & 6 & wild-type & 0 & $30 \%+$ \\
\hline 6 & $\mathrm{~F}$ & 5 & wild-type & 0 & $40 \%+$ \\
\hline 7 & M & 3 & wild-type & 0 & 0 \\
\hline 8 & M & 2 & wild-type & 0 & 0 \\
\hline 9 & $\mathrm{~F}$ & 5 & wild-type & 0 & 0 \\
\hline 10 & M & 41 & wild-type & 0 & $5-10 \%+$ \\
\hline 11 & M & 2 & wild-type & 0 & $100 \%+$ \\
\hline 12 & $\mathrm{~F}$ & 5 & wild-type & 0 & 0 \\
\hline 13 & $\mathrm{~F}$ & 6 & wild-type & 0 & 0 \\
\hline 14 & M & 12 & wild-type & 0 & $40-50 \%+$ \\
\hline 15 & M & 35 & wild-type & 0 & $10 \%+$ \\
\hline
\end{tabular}

M: male, F: female, 0: absence of staining.

for $\mathrm{p} 16^{\mathrm{INK} 4}$ was detected in all metanephric adenomas (range from $5 \%$ to $100 \%$ of cells), which manifested as nuclear or cytoplasmic staining or both. On the other hand, $\mathrm{p} 16^{\mathrm{INK} 4}$ immunostaining was demonstrated in 8 of 15 (53\%) epithelial-predominant nephroblastomas.

The histopathological characteristics, molecular and immunohistochemical results are detailed in Table 1 and in Table 2.

\section{DISCUSSION}

$B R A F$ is an oncogene that normally functions as a regulator of cell division and differentiation through its role in the MAP kinase pathway. Mutations in this gene, which lead to constitutive activation of downstream signaling within this pathway, were most famously implicated in the development of melanoma [14]. Several specific pro-oncogenic mutations of $B R A F$ have since been identified and implicated in the development of a variety of solid and hematopoietic neoplasms [14, 30-32]. The vast majority, however, are characterized by a thymineto-adenine transversion at exon 15 , which results in an amino acid substitution of valine (V) for glutamic acid (E) at codon V600 (V600E) [14]. It is worth noting that clinical trials have recently emerged proposing targeted therapy for nonmelanoma cancers harboring $B R A F$ mutations, demonstrating the important role of $B R A F$ testing [33].
Attention to the association of $B R A F$ mutation with metanephric adenoma has been drawn by a few case reports and small series $[7,8,10,11,34]$. The current study, which tested 48 cases of metanephric adenoma for $B R A F$ mutation, is the largest of its kind. Molecular testing demonstrated that $85 \%$ of these tumors harbored a $B R A F$ mutation; a number in line with the findings of Choueiri et al. [7], who described this mutation in 26 of 29 cases $(89 \%)$, but somewhat lower than the remaining cases in the literature, which cumulatively yielded a mutated BRAF in 22 of 24 cases (92\%) (Table 3). All the $B R A F$-mutated cases in this study carried the same V600E mutation, which again is in keeping with the findings of almost all prior studies [7, 9-11, 34]. Of note, Udager et al. [8] identified $B R A F$ V600D in 2 of $10 B R A F$-mutated metanephric adenomas. The current study, which looked for the most common variants, including the V600D, did not find this or any other $B R A F$ mutation variant. In this study we also provided clinical and morphologic features characteristic of each metanephric adenoma subset. We found that $B R A F$-mutated cases were associated with older age whereas $B R A F$ wild-type metanephric adenomas presented earlier. Consistent with our findings, Choueiri et al. showed increased age (55 vs 33 years) in patients harboring a $B R A F$ mutation [7]. A correlation between $B R A \mathrm{~F}$ mutation status and tumor size has been proposed [7], though the current study did not show any size difference, a discrepancy that probably resulted from the 
limited number of $B R A F$-wild-type cases presented in the prior study. With regards to gender, this is the first study to demonstrate a strong male predominance in metanephric adenomas that are $B R A F$ wild-type. Other studies have shown $B R A F$ mutation in 3 of 3 and 4 of 5 male subjects respectively $[7,8]$, however the present study, which included 17 males, is the largest to test for $B R A F$ in a male cohort. Also, we included 4 pediatric cases $(<12$ years old) in our series. As in adults, $B R A F$ mutation has been reported in pediatric metanephric adenomas [11]. For the first time, we have outlined distinct morphological features characteristic of $B R A F$-mutated and $B R A F$-wildtype metanephric adenomas. There was a predominance of acinar architecture $(\mathrm{p}=0.003)$ associated with $B R A F$ mutated metanephric adenomas. The combination of solid architecture with psammoma bodies and background
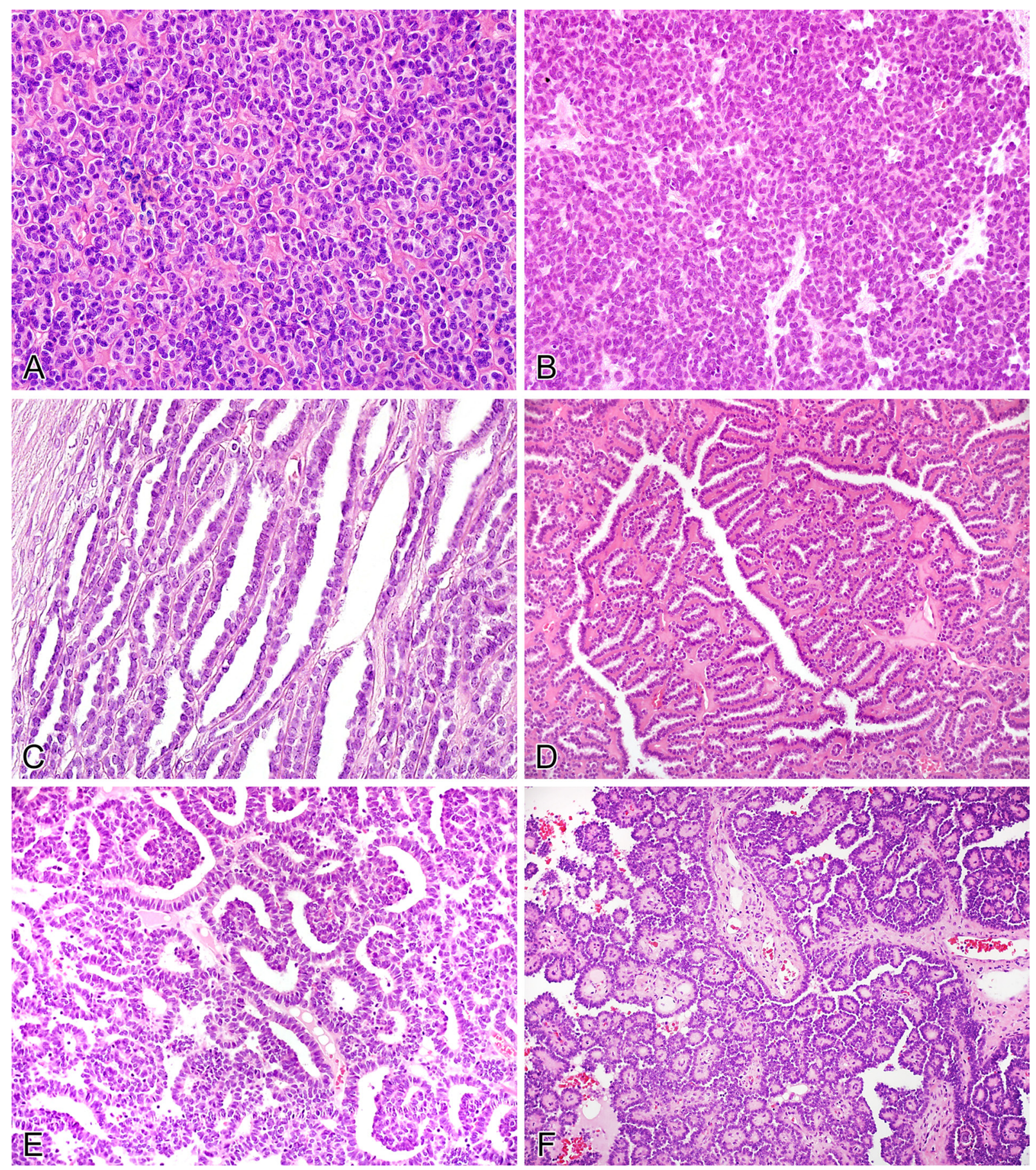

Figure 1: Histopathological features of metanephric adenoma. A. Acinar pattern. B. Solid-like area. C. Elongated tubules. D. Tubules with branching contours. E. Glomeruloid bodies. F. Papillary structures. 
hyalinized stroma was found to occur with greater frequency in $B R A F$-wild-type cases, but the difference did not reach statistical significance.

The presence of a specific and consistent mutation implies a potential role for immunohistochemistry, with the VE1 antibody, as a surrogate for molecular testing, particularly in instances where limited tissue is available or the molecular method for $B R A F$ mutation detection is not accessible. Several studies have demonstrated excellent concordance between immunostaining and mutation status in a variety of other neoplasms [25-29]. In the current study, 33 of $41 B R A F$-mutated cases were positive by immunohistochemistry. Despite it having been speculated that VE1 would be valuable diagnostically [9], this study demonstrated that VE1 antibody is a very specific (100\%) but less sensitive $(80 \%)$ marker for identifying $B R A F$ mutated metanephric adenomas. Moreover, a subset $(15 \%)$ of metanephric adenomas does not have BRAF mutation, prompting again careful use as a diagnostic tool. None of epithelial-predominant nephroblastomas was positive for $B R A F$ mutation using either molecular or immunohistochemistry methods in current study. Previous investigations also found that nephroblastomas were negative for $B R A F$ mutation by molecular assays $[34,35]$.

Another aspect of the BRAF V600E mutation is its ability to act not only as an oncogene, but paradoxically, to induce cellular senescence. This has been well studied and documented in various $B R A F$-driven neoplasms [36-41]. One of the major markers shown to identify $B R A F$-induced senescence is $\mathrm{p} 16^{\mathrm{INK} 4}$ [36]. In light of the indolent clinical course and high frequency of $B R A F$ mutation in metanephric adenomas, all cases were stained with the p16 $6^{\mathrm{INK} 4}$ antibody. We found that every metanephric adenoma was positive for this marker. The fact that even $B R A F$-wild-type tumors also exhibited positive staining with $\mathrm{p} 16^{\mathrm{INK} 4}$ suggests that mechanisms

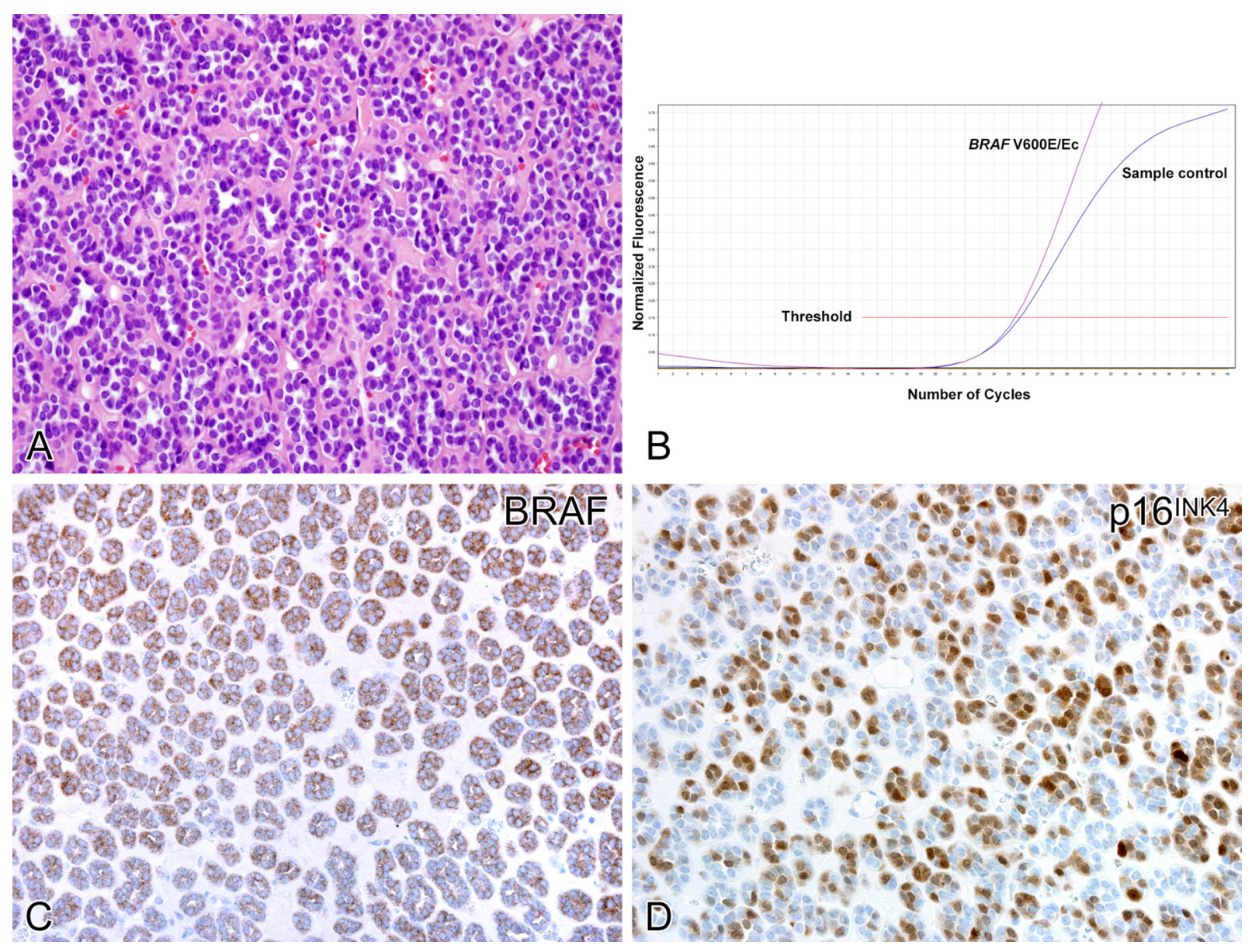

Figure 2: Molecular and immunohistochemical findings in metanephric adenoma. Metanephric adenoma predominantly composed of acini harboring $B R A F$ mutation A. Detection of $B R A F \mathrm{~V} 600 \mathrm{E} / \mathrm{Ec}$ mutation B. Fluorescence is detected during cycling for both the sample (purple) and sample control (blue). A $\leq 7.0$ difference between the crossing threshold cycles is an acceptable cutoff for a positive $\mathrm{V} 600 \mathrm{E} / \mathrm{Ec}$ result. The calculated delta $\mathrm{CT}$ value of these samples (0.34) demonstrates the detection of $\mathrm{V} 600 \mathrm{E} / \mathrm{Ec} B R A F$ mutation in relation to the sample control. The same case showed a strong cytoplasmic positivity for BRAF VE1 staining $\mathbf{C}$. and strong nuclear expression of p16 $6^{\text {INK4 }}$ immunolabeling D. 
Table 3: Metanephric neoplasms harboring $B R A F$ mutations: literature review

\begin{tabular}{|c|c|c|c|c|c|c|c|c|}
\hline Source, yr & $\begin{array}{c}\text { Number of } \\
\text { cases }\end{array}$ & $\begin{array}{l}\text { Median age } \\
\text { (year, range) }\end{array}$ & Gender & $\begin{array}{l}\text { Tumor size } \\
\text { (cm, range) }\end{array}$ & $\begin{array}{c}\text { BRAF } \\
\text { mutation }\end{array}$ & $\begin{array}{c}\text { Type of } \\
\text { mutation }\end{array}$ & $\begin{array}{c}\text { VE1 } \\
\text { positivity }\end{array}$ & Diagnosis \\
\hline $\begin{array}{l}\text { Choueiri et al., } \\
2012\end{array}$ & 29 & $54(25-78)$ & $26 \mathrm{~F} 3 \mathrm{M}$ & $2.7(1.2-7)$ & $26(89 \%)$ & V600E & NA & MA \\
\hline $\begin{array}{l}\text { Dadone et al., } \\
2013\end{array}$ & 1 & 61 & $\mathrm{~F}$ & 3.5 & $1(100 \%)$ & V600E & NA & MA \\
\hline $\begin{array}{l}\text { Pinto et al., } \\
2015\end{array}$ & 6 & 52 & $6 \mathrm{~F}$ & 2.6 & $6(100 \%)$ & V600E & $6(100 \%)$ & MA \\
\hline $\begin{array}{l}\text { Udager et al., } \\
2015\end{array}$ & 11 & $45(16-84)$ & $6 \mathrm{~F} 5 \mathrm{M}$ & $2.7(1.3-5.1)$ & $10(91 \%)$ & $\begin{array}{l}\text { V600E (8) } \\
\text { V600D (2) }\end{array}$ & $8(88 \%)$ & MA \\
\hline \multirow[t]{2}{*}{$\begin{array}{l}\text { Chami et al., } \\
2015\end{array}$} & 3 & $9(4-10)$ & $1 \mathrm{~F} 2 \mathrm{M}$ & NA (2-4.5) & $2(67 \%)$ & V600E & $2(100 \%)$ & MA \\
\hline & 1 & 4 & $1 \mathrm{M}$ & 3.1 & $1(100 \%)$ & V600E & $1(100 \%)$ & MAF \\
\hline \multirow[t]{2}{*}{$\begin{array}{l}\text { Mangray et al., } \\
2015\end{array}$} & 1 & 10 & $\mathrm{~F}$ & 1.1 & $1(100 \%)$ & V600E & $1(100 \%)$ & MAF \\
\hline & 3 & NA & NA & NA & $3(100 \%)$ & V600E & NA & MA \\
\hline Current study & 48 & $54(5-84)$ & $\begin{array}{l}31 \mathrm{~F} \\
17 \mathrm{M}\end{array}$ & $4(1.1-8)$ & $41(85 \%)$ & V600E & $33(80 \%)$ & MA \\
\hline
\end{tabular}

MA metanephric adenoma; MAF metanephric adenofibroma; M male; F female; NA not available.

for oncogene-induced senescence independent of $B R A F$ mutation exist. In addition, approximately half of the epithelial-predominant nephroblastomas were positive for $\mathrm{p} 16^{\mathrm{INK} 4}$, illustrating again that alternative modes of senescence induction may be involved. Interestingly, p16 $6^{\text {INK4 }}$ expression has been shown to correlate with good prognosis in nephroblastoma [42]. The mechanism by which some nephroblastomas evade the senescence pathways remains unknown [43].

In summary, we have identified distinct clinicopathologic patterns associated with BRAFmutated metanephric adenoma. These include older age, female predominance, and the presence of a prominent acinar component. A subset of $B R A F$-mutated metanephric adenomas $(20 \%)$ was not detected by VE1 immunostaining. p16 $6^{\mathrm{INK} 4}$ immunostaining was uniformly positive in all metanephric adenomas.

\section{MATERIALS AND METHODS}

\section{Patients and samples}

Forty-eight cases of metanephric adenoma and fifteen cases of epithelial-predominant nephroblastoma were collected from participating institutions. For each case of metanephric adenoma, the following morphologic features were recorded: the presence or absence of a pseudocapsule, foamy histiocytes, and fibrous septa; the relative proportion of stroma and its being either edematous or hyalinized; the presence and quantity of psammoma bodies; and the architectural patterns. With respect to architecture, specific patterns were recognized including tubules with or without complex branching, acini, glomeruloid structures (short, rounded papillae projecting into small cysts), solid-like (tightly packed acini with overlapping nuclei), and papillary. When present, the proportion of the tumor made up of each of these patterns was recorded as a percentage. A pattern that was greater than $50 \%$ within the tumor was considered predominant. This research was approved by the Institutional Review Board.

\section{Immunohistochemistry}

Immunohistochemical analysis was performed on all cases utilizing the VE1 antibody, which recognizes the BRAF V600E mutant protein (Spring Bioscience, Pleasanton, CA, USA), on whole tissue sections. BRAF V600E-mutated melanoma tissue was stained concurrently to serve as a positive control. Cytoplasmic staining was scored as 0 (negative), $1+$ (weak), 2+ (moderate) or 3+ (strong) [25]. A positive result required both cytoplasmic staining in $>10 \%$ of tumor cells and moderate to strong intensity, as previously described [44-46]. In addition, immunohistochemical staining for $\mathrm{p} 16^{\mathrm{INK} 4}\left(\mathrm{CINtec}^{\circledR}\right.$, Roche, Germany) was performed on whole sections for 
each case, and the percentage of positive-staining tumor cells was recorded.

\section{High resolution melting test for $B R A F$ mutational analysis}

The BRAF mutations were analyzed using realtime PCR-high resolution melting test. Areas of tumor in each case designated for testing were circled on hematoxylin and eosin-stained slides by a pathologist (LC). The DNA extractions were run using the BRAF RGQ PCR Kit (Qiagen, Valencia, CA), designed to detect somatic mutations of the $B R A F$ gene using realtime polymerase chain reaction with the Rotor-Gene Q 5plex HRM instrument. DNA concentrations were analyzed by the NanoDrop ND-1000 Spectrophotometer (NanoDrop Technologies, Wilmington, DE). Using ARMS (Amplification Refractory Mutation System) and Scorpions technologies, the BRAF RGQ PCR Kit detects mutations at codon 600 of the $B R A F$ oncogene against a background of wild type genomic DNA. The specific mutations detected by this assay are V600E/ V600E complex (V600E/Ec), V600D, V600K, and V600R. All procedures were performed according to the manufacturer's protocol.

\section{Statistical analysis}

Fisher's exact test was used to compare categorical data for clinicopathologic characteristics between $B R A F$ mutated and $B R A F$-wild-type subgroups and Student's t test to compare continuous data. All $P$ values were based on a two-sided hypothesis.

\section{CONFLICTS OF INTEREST}

Authors declare no conflicts of interest.

\section{REFERENCES}

1. Jones EC, Pins M, Dickersin GR, Young RH. Metanephric adenoma of the kidney. A clinicopathological, immunohistochemical, flow cytometric, cytogenetic, and electron microscopic study of seven cases. Am J Surg Pathol. 1995; 19:615-626.

2. Grignon DJ, Eble JN. Papillary and metanephric adenomas of the kidney. Semin Diagn Pathol. 1998; 15:41-53.

3. Davis CJ Jr, Barton JH, Sesterhenn IA, Mostofi FK. Metanephric adenoma. Clinicopathological study of fifty patients. Am J Surg Pathol. 1995; 19:1101-1114.

4. Bostwick DG, Cheng L. Urologic Surgical Pathology. $3^{\text {rd }}$ edition, Philadelphia, PA, Elsevier, 2014.

5. Kinney SN, Eble JN, Hes O, Williamson SR, Grignon DJ, Wang M, Zhang S. Metanephric adenoma: the utility of immunohistochemical and cytogenetic analyses in differential diagnosis, including solid variant papillary renal cell carcinoma and epithelial-predominant nephroblastoma. Mod Pathol. 2015; 28:1236-1248.

6. Brunelli M, Eble JN, Zhang S, Martignoni G, Cheng L. Metanephric adenoma lacks the gains of chromosomes 7 and 17 and loss of $Y$ that are typical of papillary renal cell carcinoma and papillary adenoma. Mod Pathol. 2003; 16:1060-1063.

7. Choueiri TK, Cheville J, Palescandolo E, Fay AP, Kantoff PW, Atkins MB, McKenney JK. BRAF mutations in metanephric adenoma of the kidney. Eur Urol. 2012; 62:917-922.

8. Udager AM, Pan J, Magers MJ, Palapattu GS, Morgan TM, Montgomery JS, Weizer AZ. Molecular and immunohistochemical characterization reveals novel BRAF mutations in metanephric adenoma. Am J Surg Pathol. 2015; 39:549-557.

9. Pinto A, Signoretti S, Hirsch MS, Barletta JA. Immunohistochemical staining for BRAF V600E supports the diagnosis of metanephric adenoma. Histopathology. 2015; 66:901-904.

10. Dadone B, Ambrosetti D, Carpentier X, Duranton-Tanneur V, Burel-Vandenbos F, Amiel J, Pedeutour F. A renal metanephric adenoma showing both a 2p16e24 deletion and BRAF V600E mutation: a synergistic role for a tumor suppressor gene on chromosome $2 \mathrm{p}$ and BRAF activation? Cancer Genet. 2013; 206:347-352.

11. Chami R, Yin M, Marrano P, Teerapakpinyo C, Shuangshoti $\mathrm{S}$, Thorner PS. BRAF mutations in pediatric metanephric tumors. Hum Pathol. 2015; 46:1153-1161.

12. Argani P, Lee J, Netto GJ, Zheng G, Tseh-Lin M, Park BH. Frequent BRAF V600E Mutations in Metanephric Stromal Tumor. Am J Surg Pathol. 2016.

13. Kumar R, Angelini S, Snellman E, Hemminki K. BRAF mutations are common somatic events in melanocytic nevi. J Invest Dermatol. 2004; 122:342-348.

14. Davies H, Bignell GR, Cox C, Stephens P, Edkins S, Clegg $\mathrm{S}$, Teague J. Mutations of the BRAF gene in human cancer. Nature. 2002; 417:949-954.

15. Kimura ET, Nikiforova MN, Zhu Z, Knauf JA, Nikiforov YE, Fagin JA. High prevalence of BRAF mutations in thyroid cancer: genetic evidence for constitutive activation of the RET/PTC-RAS-BRAF signaling pathway in papillary thyroid carcinoma. Cancer Res. 2003; 63:1454-1457.

16. Schindler G, Capper D, Meyer J, Janzarik W, Omran H, Herold-Mende C, Schmieder K. Analysis of BRAF V600E mutation in 1,320 nervous system tumors reveals high mutation frequencies in pleomorphic xanthoastrocytoma, ganglioglioma and extra-cerebellar pilocytic astrocytoma. Acta Neuropathol. 2011; 121:397-405.

17. Chan TL, Zhao W, Leung SY, Yuen ST, Cancer Genome P. BRAF and KRAS mutations in colorectal hyperplastic 
polyps and serrated adenomas. Cancer Res. 2003; 63:4878-4881.

18. Tannapfel A, Sommerer F, Benicke M, Katalinic A, Uhlmann D, Witzigmann H, Hauss J. Mutations of the BRAF gene in cholangiocarcinoma but not in hepatocellular carcinoma. Gut. 2003; 52:706-712.

19. Singer G, Oldt R 3rd, Cohen Y, Wang BG, Sidransky D, Kurman RJ, Shih IeM. Mutations in BRAF and KRAS characterize the development of low-grade ovarian serous carcinoma. J Natl Cancer Inst. 2003; 95:484-486.

20. Paik PK, Arcila ME, Fara M, Sima CS, Miller VA, Kris MG, Ladanyi M. Clinical characteristics of patients with lung adenocarcinomas harboring BRAF mutations. J Clin Oncol. 2011; 29:2046-2051.

21. Badalian-Very G, Vergilio JA, Degar BA, MacConaill LE, Brandner B, Calicchio ML, Kuo FC. Recurrent BRAF mutations in Langerhans cell histiocytosis. Blood. 2010; 116:1919-1923

22. Tiacci E, Trifonov V, Schiavoni G, Holmes A, Kern W, Martelli MP, Pucciarini A. BRAF mutations in hairy-cell leukemia. N Engl J Med. 2011; 364:2305-2315.

23. Ritterhouse LL, Barletta JA. BRAF V600E mutationspecific antibody: A review. Semin Diagn Pathol. 2015; 32:400-408.

24. Routhier CA, Mochel MC, Lynch K, Dias-Santagata D, Louis DN, Hoang MP. Comparison of 2 monoclonal antibodies for immunohistochemical detection of BRAF V600E mutation in malignant melanoma, pulmonary carcinoma, gastrointestinal carcinoma, thyroid carcinoma, and gliomas. Hum Pathol. 2013; 44:2563-2570.

25. Pearlstein MV, Zedek DC, Ollila DW, Treece A, Gulley ML, Groben PA, Thomas NE. Validation of the VE1 immunostain for the BRAF V600E mutation in melanoma. J Cutan Pathol. 2014; 41:724-732.

26. Goeppert B, Frauenschuh L, Renner M, Roessler S, Stenzinger A, Klauschen F, Warth A. BRAF V600Especific immunohistochemistry reveals low mutation rates in biliary tract cancer and restriction to intrahepatic cholangiocarcinoma. Mod Pathol. 2014; 27:1028-1034.

27. Lasota J, Kowalik A, Wasag B, Wang ZF, Felisiak-Golabek A, Coates T, Kopczynski J. Detection of the BRAF V600E mutation in colon carcinoma: critical evaluation of the imunohistochemical approach. Am J Surg Pathol. 2014; 38:1235-1241.

28. Roden $\mathrm{AC}, \mathrm{Hu} \mathrm{X}$, Kip $\mathrm{S}$, Parrilla Castellar ER, Rumilla KM, Vrana JA, Vassallo R. BRAF V600E expression in Langerhans cell histiocytosis: clinical and immunohistochemical study on 25 pulmonary and 54 extrapulmonary cases. Am J Surg Pathol. 2014; 38:548-551.

29. Capper D, Preusser M, Habel A, Sahm F, Ackermann U, Schindler G, Pusch S. Assessment of BRAF V600E mutation status by immunohistochemistry with a mutation-specific monoclonal antibody. Acta Neuropathol. 2011; 122:11-19.

30. Long GV, Menzies AM, Nagrial AM, Haydu LE, Hamilton AL, Mann GJ, Hughes TM. Prognostic and clinicopathologic associations of oncogenic BRAF in metastatic melanoma. J Clin Oncol. 2011; 29:1239-1246.

31. Greaves WO, Verma S, Patel KP, Davies MA, Barkoh BA, Galbincea JM, Yao H. Frequency and spectrum of BRAF mutations in a retrospective, single-institution study of 1112 cases of melanoma. J Mol Diagn. 2013; 15:220-226.

32. Bradish JR, Cheng L. Molecular pathology of malignant melanoma: changing the clinical practice paradigm toward a personalized approach. Hum Pathol. 2014; 45:1315-1326.

33. Hyman DM, Puzanov I, Subbiah V, Faris JE, Chau I, Blay JY, Wolf J. Vemurafenib in Multiple Nonmelanoma Cancers with BRAF V600 Mutations. N Engl J Med. 2015; 373:726-736.

34. Mangray S, Breese V, Jackson CL, Lombardo K, Taliano R, Resnick M, Yakirevich E. Application of BRAF V600E Mutation Analysis for the Diagnosis of Metanephric Adenofibroma. Am J Surg Pathol. 2015; 39:1301-1304.

35. Miao J, Kusafuka T, Fukuzawa M. Hotspot mutations of BRAF gene are not associated with pediatric solid neoplasms. Oncol Rep. 2004; 12:1269-1272.

36. Michaloglou C, Vredeveld LC, Soengas MS, Denoyelle C, Kuilman T, van der Horst CM, Majoor DM. BRAFE600associated senescence-like cell cycle arrest of human naevi. Nature. 2005; 436:720-724.

37. Chilosi M, Facchetti F, Calio A, Zamo A, Brunelli M, Martignoni G, Rossi A. Oncogene-induced senescence distinguishes indolent from aggressive forms of pulmonary and non-pulmonary Langerhans cell histiocytosis. Leuk Lymphoma. 2014; 55:2620-2626.

38. Zeppernick F, Ardighieri L, Hannibal CG, Vang R, Junge J, Kjaer SK, Zhang R. BRAF mutation is associated with a specific cell type with features suggestive of senescence in ovarian serous borderline (atypical proliferative) tumors. Am J Surg Pathol. 2014; 38:1603-1611.

39. Raabe EH, Lim KS, Kim JM, Meeker A, Mao XG, Nikkhah $\mathrm{G}$, Maciaczyk J. BRAF activation induces transformation and then senescence in human neural stem cells: a pilocytic astrocytoma model. Clin Cancer Res. 2011; 17:3590-3599.

40. Kriegl L, Neumann J, Vieth M, Greten FR, Reu S, Jung A, Kirchner T. Up and downregulation of p16(Ink4a) expression in BRAF-mutated polyps/adenomas indicates a senescence barrier in the serrated route to colon cancer. Mod Pathol. 2011; 24:1015-1022.

41. Cangi MG, Biavasco R, Cavalli G, Grassini G, Dal-Cin E, Campochiaro C, Guglielmi B. BRAFV600E-mutation is invariably present and associated to oncogene-induced senescence in Erdheim-Chester disease. Ann Rheum Dis. 2015; 74:1596-1602. 
42. Arcellana-Panlilio MY, Egeler RM, Ujack E, Pinto A, Demetrick DJ, Robbins SM, Coppes MJ. Decreased expression of the INK4 family of cyclin-dependent kinase inhibitors in Wilms tumor. Genes Chromosomes Cancer. 2000; 29:63-69.

43. Aiden AP, Rivera MN, Rheinbay E, Ku M, Coffman EJ, Truong TT, Vargas SO. Wilms tumor chromatin profiles highlight stem cell properties and a renal developmental network. Cell Stem Cell. 2010; 6:591-602.

44. Fisher KE, Neill SG, Ehsani L, Caltharp SA, Siddiqui MT, Cohen C. Immunohistochemical Investigation of BRAF p.V600E mutations in thyroid carcinoma using 2 separate BRAF antibodies. Appl Immunohistochem Mol Morphol. 2014; 22:562-567.
45. Ardighieri L, Zeppernick F, Hannibal CG, Vang R, Cope L, Junge J, Kjaer SK. Mutational analysis of BRAF and KRAS in ovarian serous borderline (atypical proliferative) tumours and associated peritoneal implants. J Pathol. 2014; 232:16-22.

46. Ehsani L, Cohen C, Fisher KE, Siddiqui MT. BRAF mutations in metastatic malignant melanoma: comparison of molecular analysis and immunohistochemical expression. Appl Immunohistochem Mol Morphol. 2014; 22:648-651. 